\title{
Botrytis cinerea Infection of Grape Flowers: Light and Electron Microscopical Studies of Infection Sites
}

\author{
Olivier Viret, Markus Keller, V. Gunta Jaudzems, and F. Mary Cole
}

First author: Agroscope RAC-Changins, Swiss Federal Agricultural Research Station, 1260 Nyon 1, Switzerland; second author: Washington State University, Prosser 99350; third author: Monash University, Clayton, Victoria 3800, Australia; and fourth author: Monash University, Frankston, Victoria 3199, Australia. Accepted for publication 5 April 2004.

\begin{abstract}
Viret, O., Keller, M., Jaudzems, V. G., and Cole, F. M. 2004. Botrytis cinerea infection of grape flowers: Light and electron microscopical studies of infection sites. Phytopathology 94:850-857.

Specific floral organs including the calyptra, stigma, and receptacle area of glasshouse-grown grapevines (Vitis vinifera cv. Cabernet Sauvignon) were inoculated with aqueous suspensions of Botrytis cinerea conidia, and the initial steps involved in colonization and infection of the host tissues were studied for several days postinoculation using light microscopy as well as scanning and transmission electron microscopy. Conidia germinated on all floral organs examined and became attached to the host surface within $48 \mathrm{~h}$ after inoculation. However, in all cases the

interior where the ovary joined the receptacle. Very few conidial germ tubes were detected in the style following inoculation of the stigma, and no evidence for their growth toward the ovaries could be found. In contrast, hyphae were more abundant in the receptacle area, regardless of the site of inoculation. Tips of the calyx became necrotic and mycelium formed in the gap between ovary and calyx within $72 \mathrm{~h}$ following inoculation, providing a major point of colonization and infection. $B$. cinerea colonized dehiscent calyptras within $72 \mathrm{~h}$ of inoculation, providing a potential source of inoculum from calyptras that remained stuck in the cluster. The results suggest that the grape flower's receptacle area is the predominant site of infection for $B$. cinerea, although a minor portion of infections may also occur through the stigma and style.
\end{abstract} vast majority of conidia accumulated in a channel-like gap between the ovary and the calyx that extended in a narrowing fashion into the flower

Botrytis cinerea Pers.:Fr. is one of the world's most important fungal pathogens, being reported on more than 230 host plants including economically important agricultural and horticultural crops (17). In grape, the disease frequently occurs on ripe berries close to harvest, following rainfalls or long period of high humidity, and develops into the characteristic gray mold. Gray mold outbreaks lead to financial losses for the growers, reducing not only yield but also grape quality. The control of gray mold in grape has always been a challenge, related to the particularities of the pathogen's biology, its adaptability to various environmental conditions, its destructive potential at harvest, and the occurrence of fungicide resistance (22). A better understanding of the epidemiological development of the fungus is a key factor to improve control. In several cases, B. cinerea, being an opportunistic saprophyte, uses dehiscent flowers to invade its host $(1,2)$. Blossom infections related to dehiscent floral parts have been reported in many different fruits such as strawberry $(1,18)$, raspberry $(5)$, blueberry (13), blackcurrant (24), tomato $(9,39)$, apple $(38)$, pear (6), plum, and nectarine (10).

The epidemiological development of gray mold on grape has been well documented, but some important steps including bloom infection followed by latency until véraison are still debated $(23,30)$. In particular, the infection pathway and the site where the fungus remains in a quiescent state in the young berries remain unknown. Grape flower anatomy and the events involved in

Corresponding author: O. Viret; E-mail address: olivier.viret@ rac.admin.ch

Publication no. P-2004-0614-01R

This article is in the public domain and not copyrightable. It may be freely reprinted with customary crediting of the source. The American Phytopathological Society, 2004
Additional keywords: flower infection, gray mold, latent infection. reproduction were reviewed by Pratt (32) and Srinivasan and Mullins (36). After cap fall (the grape flower's five petals are fused to form a protective cap termed the calyptra), which generally marks the beginning of bloom in grapes, the stamens spread out and release pollen onto the stigma where germination occurs. The pollen tube penetrates the stigma and grows down the style into a mature ovule. For B. cinerea, this stylar pathway has been reported by McClellan and Hewitt (23) from field experiments as the infection pathway responsible for early Botrytis rot. In strawberry and raspberry, infection takes place at the receptacle through decaying stamens (16), but can also occur through the style (25). In contrast to these results, Jung (20) analyzed stylar infections on 61 plant species and could never find $B$. cinerea inside the ovules, even if surface secretions from the style improved germination of the conidia. Some internal compounds inhibited fungal growth, but not pollen germ tube elongation (20). On grape, Pezet and Pont (30), using autoradiography, reported that when conidia grown on ${ }^{14} \mathrm{C}$-agar were used to inoculate grape flowers, radioactive gray mold developed on ripe berries. These authors suggested that infection took place at the base of the stamens and in the receptacle area, because they never found the fungus on the stigma. Similar observations have been made under field conditions after inoculation of grape flowers where latent $B$. cinerea was found primarily in the receptacle area (21), confirming results obtained with table grapes (15) and strawberries (19). However, despite their potential importance for disease control, no histological studies on the infection pathway of $B$. cinerea in grape flowers have been published. Therefore, following the recent publication of biochemical and epidemiological evidence for primary infection in the grape flower's receptacle area (21), this paper presents a microscopical study of the infection process with the aim of observing $B$. cinerea during the initial events leading to latent infection. 


\section{MATERIALS AND METHODS}

Flower infection. Inflorescences of grapevine plants (Vitis vinifera L. cv. Cabernet Sauvignon) grown from cuttings with one shoot and one inflorescence thinned to approximately 50 flowers were inoculated at full bloom with $0.5-\mu$ d drops of conidial suspension of $B$. cinerea $\left(1.4 \times 10^{6} \mathrm{ml}^{-1}\right)$ placed on either the calyptra, stigma, or receptacle area of each individual flower as described previously (21). Conidia were suspended in sterile water containing $0.001 \%$ (vol/vol) Teepol as wetting agent, allowing a precise deposition of the conidial suspension. The same solution without conidia was applied to uninfected control flowers. Inoculation for each position was replicated separately on all flowers of three plants. The first inoculation was performed on six selected plants and uninfected controls at Charles Sturt University, Wagga Wagga (Australia) and repeated twice at Monash University, Clayton (Australia). Plants were grown in a glasshouse at $20^{\circ} \mathrm{C}$, $80 \%$ relative humidity $(\mathrm{RH})$, and a 16 -h photoperiod. Following inoculation, the inflorescences or the whole plants were incubated by enclosing them in plastic bags for $24 \mathrm{~h}$ to maintain $100 \% \mathrm{RH}$. The plastic bags were removed and the cuttings were maintained in the glasshouse. Three replicates of six flowers per treatment were collected immediately after inoculation and light microscopy (LM), scanning electron microscopy (SEM), and transmission electron microscopy (TEM) were carried out 24, 48, 72, and $96 \mathrm{~h}$ later. Ten additional flowers were sampled for pathogen isolation on potato dextrose agar (PDA).

Germination of conidia. Ten-microliter droplets of a conidial suspension were plated on PDA (five replicates) to compare germination after 24 and $48 \mathrm{~h}$ with that of the control suspensions containing $0.001 \%$ Teepol. Germination was determined by counting the number of germinated conidia out of a total of 100 conidia on three different plates. The SigmaStat software for Windows (SPSS Inc., Chicago) was used for statistical data analysis and a $t$ test $(P=0.05)$ was used to compare mean values.

LM. Flowers were collected with tweezers, and longitudinal hand-made sections of about 2 to $3 \mathrm{~mm}$ thick were made with a razor blade under a stereomicroscope $(\times 25)$. Sections were mounted in a drop of lactophenol cotton blue (33), covered with a coverslip, and observed at $\times 400$ magnification with a bright-field microscope (Zeiss Research Microscope with Olympus PM-10 photomicrographic system, Zeiss, Carnegie, Australia). Semithin sections $(2 \mu \mathrm{m}$ thick) from resin-embedded samples prepared for TEM (described below) were stained in $0.3 \%$ toluidine blue $\mathrm{O}$ in a $1 \%$ sodium tetraborate solution ( $\mathrm{pH} 9$ for Spurr's resin) applied after filtration through a sterile Millipore filter $(0.22 \mu \mathrm{m})$, dried, and rinsed with bi-distilled water before observation.

SEM. Whole inoculated flowers were immersion-fixed in 5\% glutaraldehyde in 0.03-M Pipes buffer ( $\mathrm{pH} 6.8$ to 7.0) for $2 \mathrm{~h}$ at room temperature under vacuum to facilitate infiltration of the fixative. Samples were rinsed in buffer (three times for $5 \mathrm{~min}$ ), dehydrated in a graded ethanol series (10\% steps) for $15 \mathrm{~min}$ in each step and rinsed in absolute dry ethanol (three times for $30 \mathrm{~min}$ ). Samples were then critical-point dried, mounted on aluminum stubs, and observed after sputter-coating with gold on a scanning electron microscope (Hitachi S-570; Hitachi Instruments, Hazelbrook, Australia) at 5 to $10 \mathrm{kV}$.

TEM. Samples were fixed as described for SEM, but $1 \%$ caffeine was added to the buffer to stabilize phenolic compounds in cells (26). Following three rinses of $5 \mathrm{~min}$ each with buffer, samples were postfixed in $1 \%$ osmium tetroxide in buffer for $2 \mathrm{~h}$ at room temperature, rinsed with distilled water (three times for $5 \mathrm{~min}$ ), and dehydrated in a graded ethanol series as described for SEM. Samples were washed in absolute dry acetone (30 $\mathrm{min})$ and infiltrated in 25,50 , or $75 \%$ firm-grade Spurr's resin in dry acetone and $100 \%$ resin (one time for $30 \mathrm{~min}$ and one time overnight) on an inclined rotator at $4{ }^{\circ} \mathrm{C}(35)$. Embedded samples were polymerized at 60 to $70^{\circ} \mathrm{C}$ overnight, sectioned $(80$ to $90 \mathrm{~nm}$ thick) on a Reichert Ultracut E microtome with a diamond knife (Diatome, Switzerland), and picked up on 200 to 300 mesh copper grids. Sections were stained with uranyl acetate for $10 \mathrm{~min}$, thoroughly rinsed in $50 \%$ methanol followed by lead citrate for $10 \mathrm{~min}$, and finally rinsed in distilled water (34). Flower sections were observed on a transmission electron microscope (JEOL 20 CX; JEOL, Australia) at $80 \mathrm{kV}$.

\section{RESULTS}

Germination of conidia placed on the receptacle area was similar to that observed on the stigma (Table 1). After $24 \mathrm{~h}$, germination ranged between 26 and 50\% regardless of the position of conidia application. Conidia were generally aggregated, and after $24 \mathrm{~h}$, the suspension drops placed on the stigma were concentrated on the nectaries above the receptacle area or in the channellike structure between the receptacle and the style. Conidia suspended in water containing Teepol showed reduced germination after $24 \mathrm{~h}$ on PDA compared with that of the suspension in water alone (Table 1). However, after $48 \mathrm{~h}$, germination in both suspensions was identical as shown in Table 1.

For all sampling dates and experiments, $B$. cinerea could be reisolated from infected flowers on PDA. Light microscopical observations of hand-made sections allowed a first evaluation of the germination and penetration processes on the different areas of the flowers. By $24 \mathrm{~h}$ after inoculation, germ tubes had emerged from conidia and formed appressoria-like structures on the stigma (Fig. 1A to C). Similar structures were found on the dehiscent calyptra, which sometimes remained attached to the flower during bloom. Seventy-two hours after inoculation, the dehiscent calyptras usually were completely colonized by B. cinerea (Fig. 1D). Pollen grains were abundant on the flowers, and some conidia adhered to and germinated on them. Observations made on the stigma revealed the presence of a large number of pollen grains, but only few conidia of $B$. cinerea could be detected using cotton blue staining (data not shown).

Longitudinal semithin sections of resin-embedded flowers were observed with LM to identify areas of interest for TEM. Before anthesis, the floral organs formed a closed structure, except around the calyx at the insertion point of the calyptra, where a channel-like structure formed by rudiments of the fused sepals was clearly visible (Fig. 2A to C). During anthesis, the calyptra opened from the insertion point upward. Normally it falls off, but it can remain partly attached to the calyx or on the stamens or rachis between the flowers. The style carried a papillate stigma, and at its base, the ovary was encircled by nectaries or osmophores forming a bulge (Fig. 2D). The shedding of the calyptra exposed a relatively large area of partly dehiscent tissues, such as the stamen filaments, at the insertion points of the stamens and the cap, the area between the ovary and the calyx (Fig. 2E). This layer of transition tissues was separated on the side by an open gap (Fig. 2D to F). Infected flowers consistently showed injured tissues at the tips of the calyx and at the insertion point of the stamen filaments (Fig. 2D to F), especially after inoculation in the

TABLE 1. Botrytis cinerea germination on the surface of grape floral organs as a percentage of applied conidia at various times after inoculation on the style and on the receptacle, and germination of conidia suspended in water and water amended with Teepol on potato dextrose agar (PDA) ${ }^{\mathrm{z}}$

\begin{tabular}{lcccc}
\hline Time & $\begin{array}{c}\text { Inoculation on } \\
\text { the receptacle }\end{array}$ & $\begin{array}{c}\text { Inoculation } \\
\text { on the style }\end{array}$ & $\begin{array}{c}\text { PDA, conidia } \\
\text { suspended } \\
\text { in water }\end{array}$ & $\begin{array}{c}\text { PDA, conidia } \\
\text { suspended in } \\
\text { water + Teepol }\end{array}$ \\
\hline $24 \mathrm{~h}$ & $26.3 \mathrm{c}$ & $51.9 \mathrm{c}$ & $89.7 \mathrm{a}$ & $67.3 \mathrm{~b}$ \\
$48 \mathrm{~h}$ & $35.0 \mathrm{~b}$ & $27.7 \mathrm{~b}$ & $95.3 \mathrm{a}$ & $94.3 \mathrm{a}$ \\
$72 \mathrm{~h}$ & $30.0 \mathrm{a}$ & $23.6 \mathrm{a}$ & n.d. & n.d. \\
\hline
\end{tabular}

${ }^{\mathrm{z}}$ Values followed by the same letter within a row are not significantly different $(P>0.05)$. n.d. $=$ not determined. 
receptacle area. Such injuries could not be detected on uninfected controls (Fig. 2A to C).

Observations using SEM confirmed the presence of a large gap between the calyx and the ovary after cap fall, which could act as reception trough or channel for conidia (Fig. 3A). Although the papillate surface of the stigma was designed to retain pollen grains for germination (Fig. 3B), precise inoculation on the stylar end never led to conclusive evidence of penetrating conidia. However, germinated conidia were found regularly in the receptacle region following inoculation on the stigma.

By $48 \mathrm{~h}$ after inoculation, a sheath of extracellular material was present around conidia and germ tubes in the open area of the calyx (Fig. 3C and D). Later, mycelium developed in the gap between ovary and receptacle (Fig. 3E). Conidia were also found regularly on the nectaries that protrude like a ledge from the base of the ovary (Fig. 3F). Conidia were present on the entire receptacle area following targeted inoculation at this site (Fig. 4A to F), but were particularly abundant in the space between the calyx and the ovary (Fig. 4F). Conidia were regularly found on the tips of the calyx (Fig. 4D). Germ tubes of conidia localized in the open space above the calyx may be able to penetrate into the interior part of the flower by growing between the cells of the ovary and those of the calyx (Fig. 4E).

Results obtained by TEM confirmed the presence of a gap between the calyx and the ovary, which was relatively large on the insertion point of the cap and stamen filaments, and progressively narrowed toward the interior where the ovary joined the receptacle (Fig. 5A). In some cases, this intercellular space contained dust-like material as shown in Figure 5B. Hyphae of $B$. cinerea were observed growing toward the internal tissues between receptacle and style (Fig. 5C). Generally, calyx tips, corresponding to fused sepals, were completely colonized by hyphae of the patho-
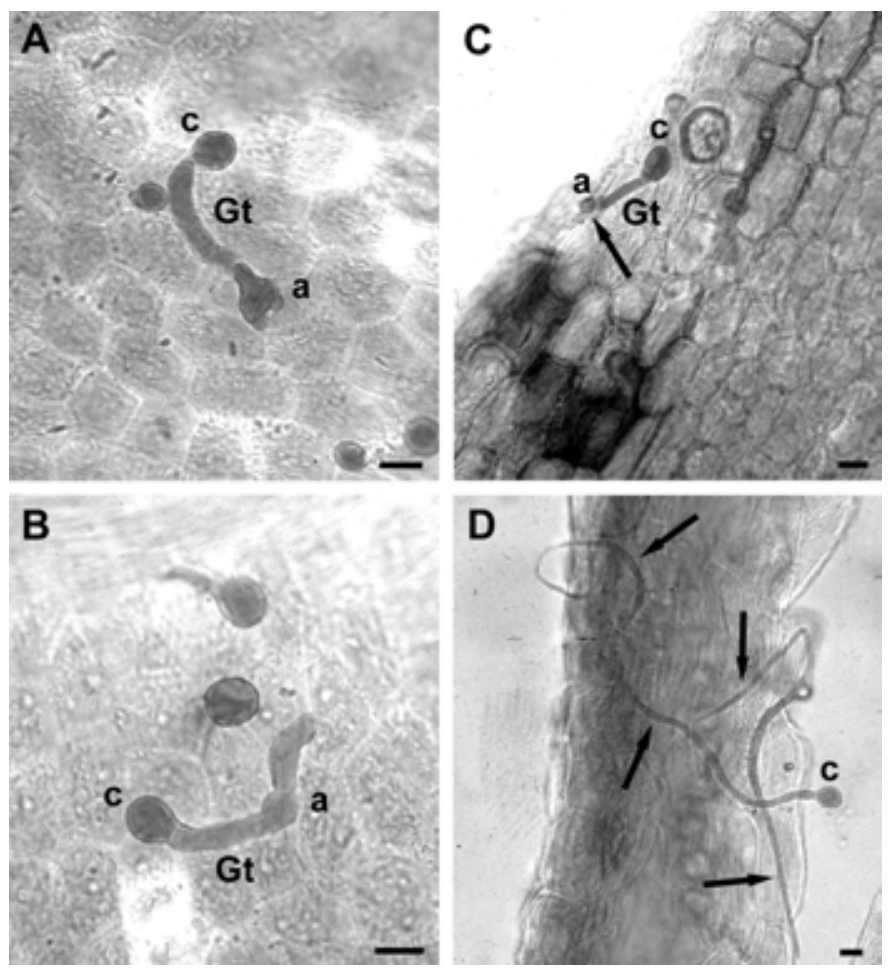

Fig. 1. Light micrographs of germination of Botrytis cinerea conidia on hand sections of inoculated grape flowers. A and B, On the stigma, an appressorialike structure (a) is formed at the end of germ tubes (Gt) by $24 \mathrm{~h}$ postinoculation (c, conidium). C and D, By $72 \mathrm{~h}$ after inoculation, germinated conidia are observed on a dehiscent calyptra remaining attached to an open flower. $\mathbf{C}$, Appressoria-like structure (a) at the end of a germ tube (arrow) growing from a conidium (c). D, Cross section of the calyptra with long hyphae (arrows) growing through the host tissue. Bars $=10 \mu \mathrm{m}$. gen growing intercellularly or intramurally in the host cell walls (Fig. 5D to F), as also was observed by LM and SEM. A similar colonization of host tissues was observed in the dehiscent calyptras when they remained partly attached to the flowers after anthesis (Fig. 6).
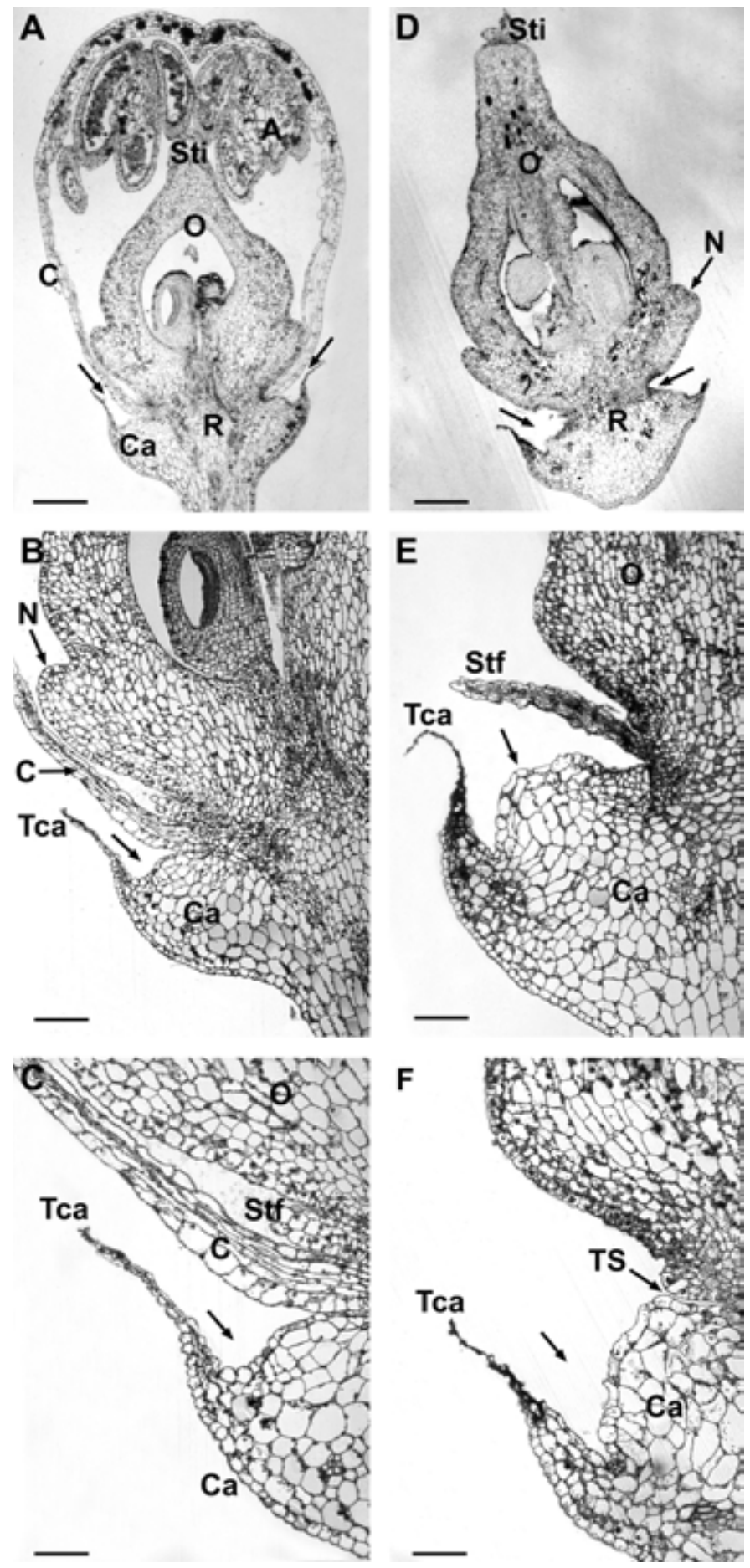

Fig. 2. Light micrographs of the morphology of grape flowers $\mathbf{A}$ to $\mathbf{C}$, before and $\mathbf{D}$ to $\mathbf{F}$, after anthesis. A to $\mathbf{C}$, An uninoculated flower at prebloom. The floral organs form a closed structure, except around the calyx $(\mathrm{Ca})$ at the insertion point of the calyptra (C), where a channel-like structure (arrows) formed by rudiments of the fused sepals (Tca) is visible. D to F, An inoculated flower following Botrytis cinerea inoculation at full bloom. Necrotic tissues are visible at the tips of the calyx (Tca) and at the insertion point of the stamen filaments (Stf). A, anthers; R, receptacle; N, nectaries or osmophores; O, ovary; Sti, stigma; and TS, transition space between ovary and calyx. Bars: $\mathbf{A}=0.5 \mathrm{~mm}, \mathbf{B}=0.2 \mathrm{~mm}, \mathbf{C}=0.1 \mathrm{~mm}, \mathbf{D}=0.5 \mathrm{~mm}, \mathbf{E}=0.2 \mathrm{~mm}$, and $\mathbf{F}=0.1 \mathrm{~mm}$. 


\section{DISCUSSION}

Although the presence of latent $B$. cinerea in immature grape berries was first reported by McClellan and Hewitt (23), to our knowledge, this is the first report on localization and visualization of $B$. cinerea on the different floral organs during the early infection processes in grape flowers. McClellan and Hewitt (23) described a so-called "early Botrytis rot" occurring during bloom following infection of the stigma and stylar end of the flower and remaining latent until maturation, but they did not present any microscopical evidence for this infection pathway. Pezet and Pont (30), using autoradiography, confirmed the relationship between bloom infection and disease expression at harvest and suggested the receptacle as a major infection pathway. Nair et al. (28) proposed a direct quantitative relationship between flower infection and the incidence of gray mold at harvest, without microscopical
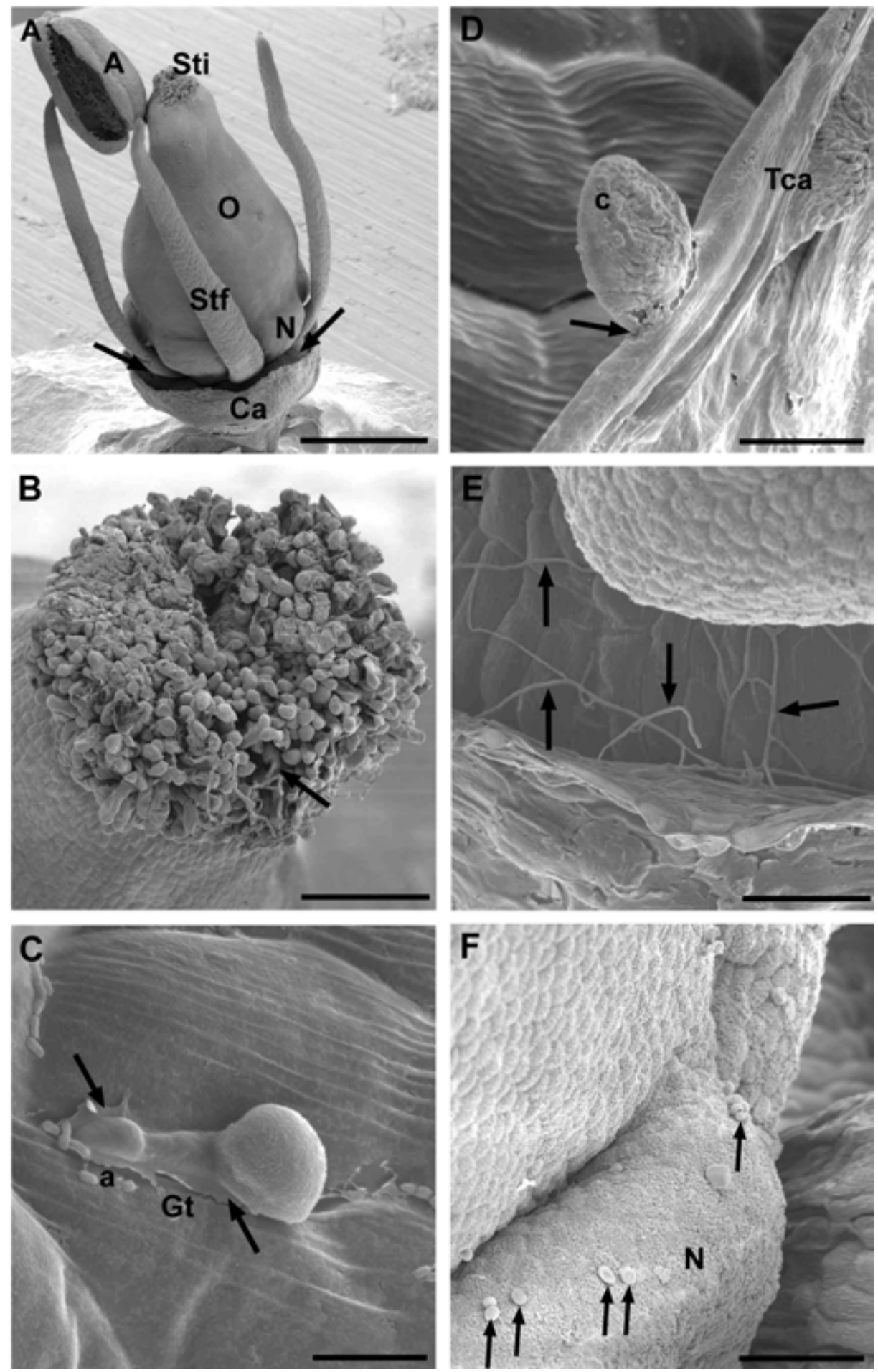

Fig. 3. Scanning electron micrographs of grape flowers inoculated with Botrytis cinerea on the stigma at full bloom. A, Overview of an open flower showing the prominent gap (arrows) between calyx (Ca) and ovary (O) at the insertion point of the stamen filaments (Stf). A, anther; Sti, stigma; and N, nectaries. B, Detail of the papillate stigma with germinating pollen grains (arrow). C, Receptacle area $48 \mathrm{~h}$ postinoculation, appressoria-like structure (a) at the end of a conidial germ tube (Gt) attached by an extracellular sheath on the host surface (arrows). D, At $72 \mathrm{~h}$ after inoculation, conidium (c) adhered (arrow) on tip of the calyx (Tca). E, View in the open channel of the calyx (Ca) $72 \mathrm{~h}$ after inoculation, with hyphae of $B$. cinerea (arrows) colonizing the host tissues. F, Conidia (arrows) accumulated on a nectary (N). Bars: $\mathbf{A}=600 \mu \mathrm{m}, \mathbf{B}=120 \mu \mathrm{m}, \mathbf{C}=8.6 \mu \mathrm{m}, \mathbf{D}=10 \mu \mathrm{m}, \mathbf{E}=50 \mu \mathrm{m}$, and $\mathbf{F}=50 \mu \mathrm{m}$. 
analysis of the infection pathway. Despite the general acceptance of bloom infection in grape, the supposed infection pathway by $B$. cinerea to date has not been investigated in detail. Most reports published on grape flowers have dealt with developmental morphology (11), ontogeny (37), or berry development after anthesis (12), without any relation to gray mold.

Based on previous results $(21,23,31)$ showing that full bloom is the most susceptible stage for infection by $B$. cinerea, the present study was limited to artificial inoculation at this phenological stage. Before bloom, grape flowers are covered by the calyptra, which separates at the base of the ovary during anthesis and generally falls off as the stamen filaments elongate. The relatively protected prebloom flower offers only restricted infection opportunities for fungal pathogens. On the other hand, the open flower presents morphological characteristics favorable for infectious fungal propagules, especially on the stigma and in the receptacle area. Cross sections through the papillate structure of the stigma were particularly difficult to obtain, but demonstrated the pres-
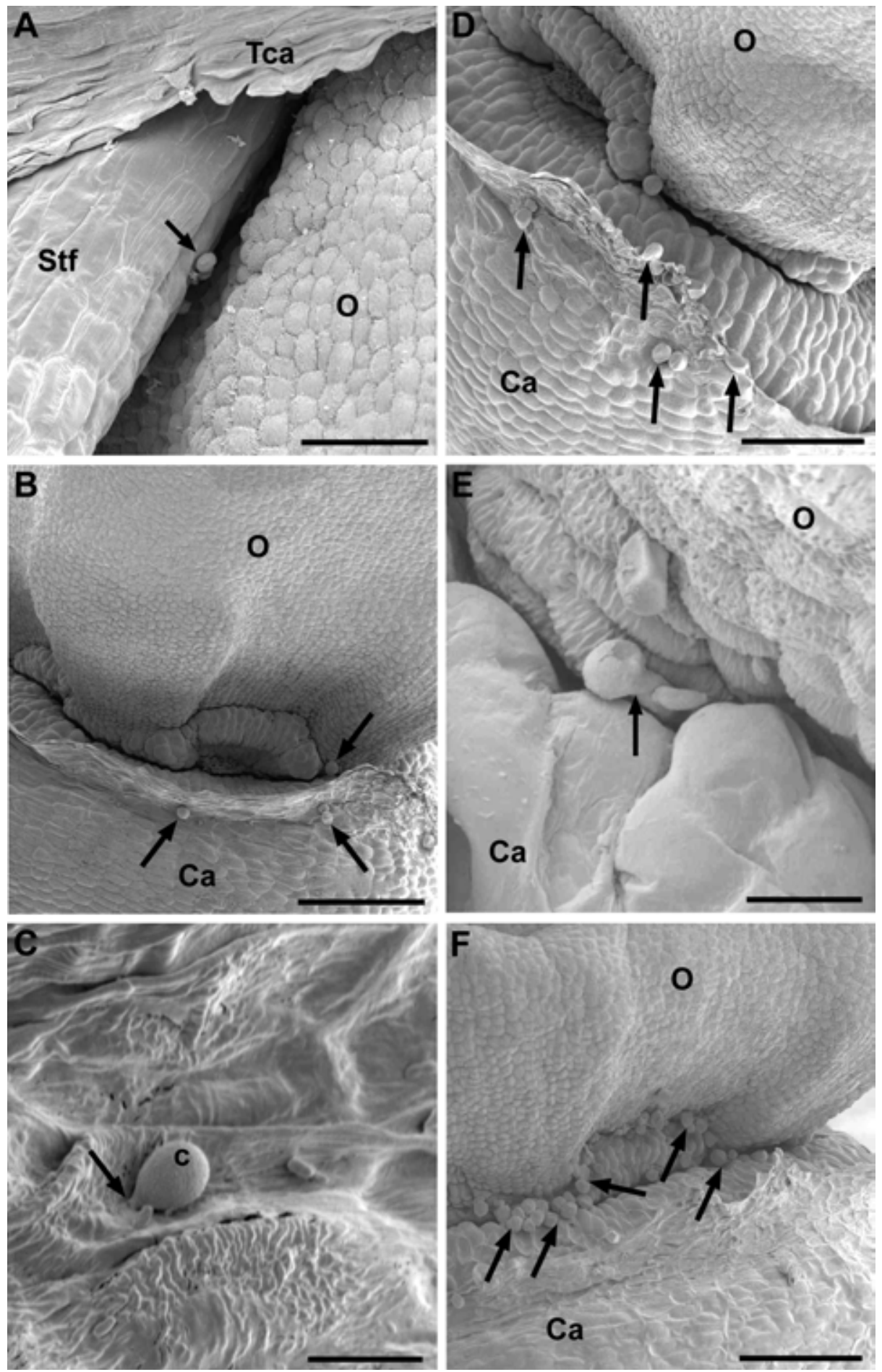

Fig. 4. Scanning electron micrographs of grape flowers inoculated with Botrytis cinerea on the receptacle area at full bloom. A, Ungerminated conidium (arrow) on the base of a stamen filament (Stf) close to the tip of the calyx (Tca). B, At $48 \mathrm{~h}$ postinoculation, conidia (arrows) in the open space between calyx (Ca) and ovary (O). C, Conidium (c) adhering to the host surface (arrow) by $48 \mathrm{~h}$ after inoculation. D, Some conidia (arrows) are concentrated on the tip of the calyx (Ca) by $48 \mathrm{~h}$ after inoculation. E, At $72 \mathrm{~h}$ postinoculation, germinated conidium (arrow) in the space between calyx $(\mathrm{Ca})$ and ovary $(\mathrm{O})$ growing toward the interior of the flower. F, Conidia (arrows) concentrated in the space between calyx $(\mathrm{Ca})$ and ovary $(\mathrm{O}) 96 \mathrm{~h}$ postinoculation. Bars: $\mathbf{A}=50 \mu \mathrm{m}, \mathbf{B}=150 \mu \mathrm{m}, \mathbf{C}=8.6 \mu \mathrm{m}, \mathbf{D}=$ $100 \mu \mathrm{m}, \mathbf{E}=12 \mu \mathrm{m}$, and $\mathbf{F}=120 \mu \mathrm{m}$. 
ence of only few hyphae of $B$. cinerea. However, although penetration through the stigma and style has been proposed as the most logical pathway for $B$. cinerea infection of grape flowers, targeted inoculation on the stigma did not lead to host defense reactions, latent infections, and disease expression (21). Jung (20), investigating anatomical infection by several fungi, including $B$. cinerea, through the style of 61 different plant species, never found fungal propagules inside the ovules. He observed that exudates on the surface of the stigma favored germination of conidia, but that inhibiting compounds present in high concentration in the internal tissues of the style prevented germ tube elongation of the fungi, but not those of the pollen grain. This could be related partly to high concentrations of calcium oxalate in the stigmatic and stylar tissues, which would contribute to an unfavorable environment for $B$. cinerea growth $(4,12)$. Moreover, suspension droplets frequently ran off the stigma, and conidia deposited there were later found on the side of the pistil or in the receptacle area. The high humidity applied during the first $24 \mathrm{~h}$
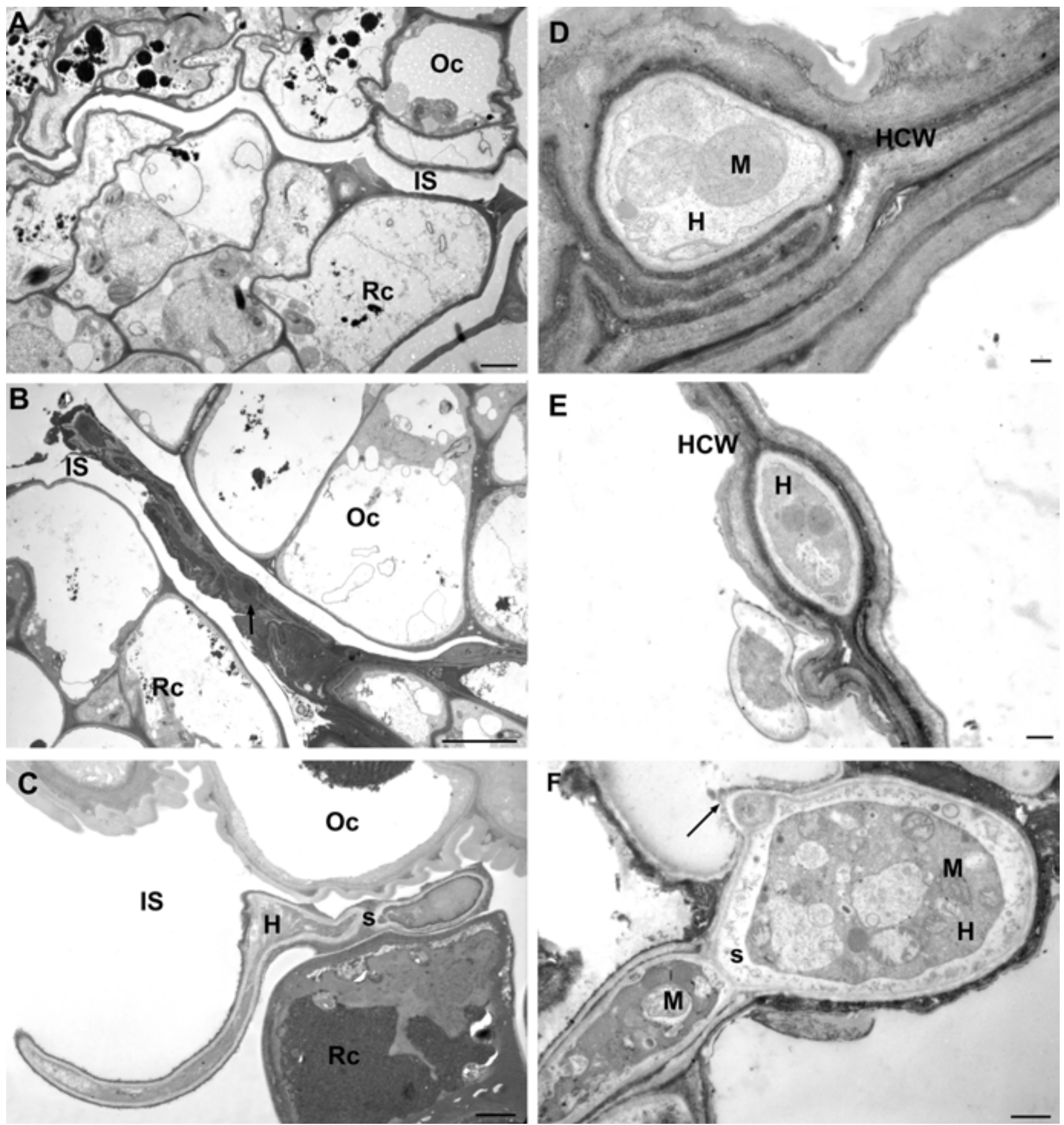

Fig. 5. Transmission electron micrographs of longitudinal sections through the receptacle area of grape flowers $72 \mathrm{~h}$ after inoculation with Botrytis cinerea. A, Transition tissues between receptacle cells (Rc) and ovary cells (Oc), showing an intercellular space (IS), wide on the outside and progressively narrowing toward the interior where the ovary joins the receptacle. B, This intercellular space (IS) appears to contain dust-like materials (arrow). C, Longitudinal section of a hypha (H) with septum (s) growing in the intercellular space (IS) between receptacle cells (Rc) and ovary cells (Oc). D, Cross section of intercellular hyphae (H) of $B$. cinerea in dehiscent calyx tip growing between host cell walls $(\mathrm{HCW})$. E, Cross section of an intramural hypha $(\mathrm{H})$ of $B$. cinerea in dehiscent calyx tip growing within the cell wall of the host $(\mathrm{HCW})$. F, Longitudinal section of a hypha $(\mathrm{H})$ with a septum (s) and mitochondria $(\mathrm{M})$ and an emerging side hypha (arrow) growing in the intercellular space of the tip of the calyx. Bars: $\mathbf{A}$ and $\mathbf{B}=10 \mu \mathrm{m}$ and $\mathbf{C}$ to $\mathbf{F}=1 \mu \mathrm{m}$. 


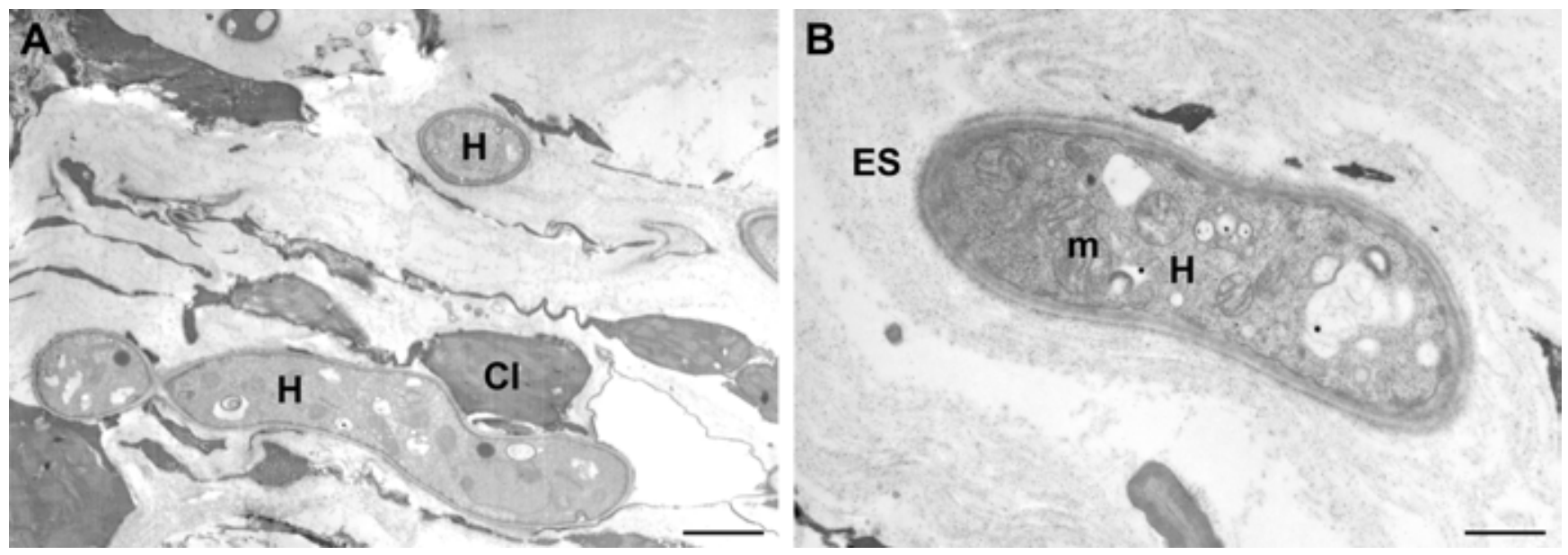

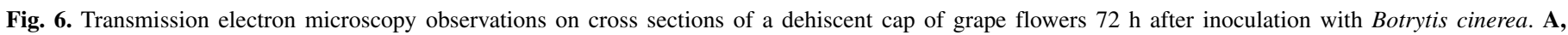

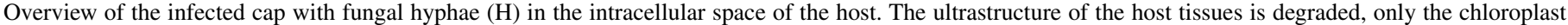
(Cl) can be recognized. B, Extracellular sheath $(\mathrm{ES})$ around the hypha $(\mathrm{H})$ of the pathogen $(\mathrm{m}$, mitochondria). Bars: $\mathbf{A}=10 \mu \mathrm{m}$ and $\mathbf{B}=5 \mu \mathrm{m}$.

after inoculation to favor germination of conidia may have provoked runoff of the droplets. This suggests that during conditions of high $\mathrm{RH}$ or rainfall during bloom, which are conducive to $B$. cinerea infection, the receptacle area could play an important role by collecting the inoculum. Raindrops or dew can also carry single conidia of $B$. cinerea (3), which could accumulate in the channel between ovary and calyx when the water evaporates. In contrast, the conidia found on the flanks of the pistil and on the nectaries and different parts of the receptacle area were attached firmly to the host surface by an extracellular matrix clearly visible at the SEM level, as reported previously by Doss et al. (8).

Histological studies of the receptacle area clearly revealed this flower part as a major penetration site for $B$. cinerea during bloom, confirming the hypothesis of Keller et al. (21), Pezet and Pont (30), and Holz et al. (15). The open structure found at the insertion point of the calyptra and stamen filaments seems to play a particularly important role. The large size (about $500 \mu \mathrm{m}$ ) of this flattened area surrounding the base of the entire flower suggests that it can contain a large number of conidia. Our investigation using SEM and TEM also demonstrated the presence of conidial germ tubes growing inside the narrowing gap between calyx and ovary. Hyphae could remain latent in this intercellular channel, contributing to the fact that $B$. cinerea often can be isolated from the receptacle area of immature berries $(15,21)$. Moreover, dehiscent tissues, such as the stamen filaments, the tips of the calyx, or the calyptras sometimes remaining partially attached or stuck in the cluster, can favor B. cinerea establishment. All of these dehiscent tissues were colonized abundantly by the fungus and represented an important source of inoculum, as indicated by Bulit and Lafon (2). Pezet and Pont (30) suggested that the fungus infects the base of the stamens and from there colonizes the receptacle area and the pedicel. The combined evidence of the present study and our earlier results (21) suggests that the grape flower's receptacle area is indeed the predominant site of infection for $B$. cinerea, although a minor portion of infections also may occur through the stigma and style. Regardless of the site of infection, a variety of defense mechanisms maintain the pathogen in a latent state in young grape berries $(14,29)$, but these mechanisms diminish during berry ripening (31). The typical gray mold symptoms generally appear as the result of expression of latent $B$. cinerea and of possible external infections from the outside of the berries (21). Rainfall during ripening is thought to accelerate the senescence processes in plant tissues (7) and is particularly favorable for the development of $B$. cinerea. In contrast, bloom infection appears to be less weather-dependent (27), and its contribution to late-season gray mold expression may diminish rapidly once a disease outbreak has occurred (21).

\section{ACKNOWLEDGMENTS}

The Australian Grape and Wine Research and Development Corporation, the Cooperative Research Centre for Viticulture, Charles Sturt University, and Monash University provided financial support in the form of a Visiting Research Fellowship for O. Viret.

\section{LITERATURE CITED}

1. Bristow, P. R., McNicol, R. J., and Williamson, B. 1986. Infection of strawberry flowers by Botrytis cinerea and its relevance to grey mould development. Ann. Appl. Biol. 109:545-554.

2. Bulit, J., and Lafon, R. 1977. Observations sur la contamination des raisins par le Botrytis cinerea Pers. Pages 61-69 in: Travaux dédiés à G. Viennot-Bourgin. Soc. Fr. Phytopathol., Paris.

3. Coertze, S., Holz, G., and Sadie, A. 2001. Germination and establishment of infection on grape berries by single airborne conidia of Botrytis cinerea. Plant Dis. 85:668-677.

4. Considine, J. A., and Knox, R. B. 1979. Development and histochemistry of the pistil of the grape, Vitis vinifera. Ann. Bot. 43:11-22.

5. Dashwood, E. P., and Fox, R. A. 1988. Infection of flowers and fruits of red raspberry by Botrytis cinerea. Plant Pathol. 37:423-430.

6. De Kock, S. L., and Holz, G. 1992. Blossom-end rot of pears: Systemic infection of flowers and immature fruit by Botrytis cinerea. J. Phytopathol. 135:317-327.

7. De Luca d'Oro, G. M., and Trippi, V. S. 1987. Effect of stress conditions induced by temperature, water and rain on senescence development. Plant Cell Physiol. 28:1389-1396.

8. Doss, R. P., Potter, S. W., Chastagner, G. A., and Christian, J. K. 1993. Adhesion of nongerminated Botrytis cinerea conidia to several substrata. Appl. Environ. Microbiol. 59:1786-1791.

9. Eden, M. A., Hill, R. A., Beresford, R., and Steward, A. 1996. The influence of inoculum concentration, relative humidity, and temperature on infection of greenhouse tomatoes by Botrytis cinerea. Plant Pathol. 45:795-806

10. Fourie, I. F., and Holz, G. 1994. Infection of plum and nectarine flowers by Botrytis cinerea. Plant Pathol. 43:309-315.

11. Gerrath, J. M. 1993. Developmental morphology and anatomy of grape flowers. Hortic. Rev. 13:315-337.

12. Hardie, W. J., O'Brien, T. P., and Jaudzems, V. G. 1996. Morphology, anatomy and development of the pericarp after anthesis in grape, Vitis vinifera L. Aust. J. Grape Wine Res. 2:97-142.

13. Hildebrand, P. D., McRae, K. B., and Lu, X. 2001. Factors affecting flower infection and disease severity of lowbush blueberry by Botrytis cinerea. Can. J. Plant Pathol. 23:364-370.

14. Hill, G., Stellwaag-Kittler, F., Huth, G., and Schlösser, E. 1981. Resistance of grapes in different developmental stages to Botrytis cinerea. Phytopathol. Z. 102:328-338.

15. Holz, G., Coertze, S., and Basson, E. J. 1997. Latent infection of Botrytis cinerea in grape pedicels leads to postharvest decay. (Abstr.) Phytopathology 87(suppl.):S43.

16. Jarvis, W. R. 1962. The infection of strawberry and raspberry fruits by Botrytis cinerea Fr. Ann. Appl. Biol. 50:569-575.

17. Jarvis, W. R. 1977. Botryotinia and Botrytis Species: Taxonomy, Physi- 
ology and Pathogenicity. Monograph 15. Research Branch Canada, Department of Agriculture, Ottawa, Ontario.

18. Jarvis, W. R., and Borecka, H. 1968. The susceptibility of strawberry flowers to infection by Botrytis cinerea Pers. ex. Fr. Hortic. Res. 8:147154.

19. Jersch, S., Scherer, C., Huth, G., and Schlösser, E. 1989. Proanthocyanidins as basis for quiescence of Botrytis cinerea in immature strawberry fruits. Z. Pflanzenkrankh. Pflanzenschutz 96:365-378

20. Jung, J. 1956. Sind Narben und Griffel Eintrittspforten für Pilzinfektionen? Phytopathol. Z. 27:405-426.

21. Keller, M., Viret, O., and Cole, F. M. 2003. Botrytis cinerea infection in grape flowers: Defense reaction, latency, and disease expression. Phytopathology 93:316-322.

22. Leroux, P., Fritz, R., Debieu, D., Albertini, C., Lanen, C., Bach, J., Gredt, M., Chapeland, F., and Hollomon, D. W. 2002. Mechanisms of resistance to fungicides in field strains of Botrytis cinerea. Pest Manag. Sci. 58:876888.

23. McClellan, W. D., and Hewitt, W. B. 1973. Early Botrytis rot of grapes: Time of infection and latency of Botrytis cinerea Pers. in Vitis vinifera L. Phytopathology 63:1151-1157.

24. McNicol, R. J., and Williamson, B. 1989. Systemic infection of blackcurrant flowers by Botrytis cinerea and its involvement in premature abscission of fruits. Ann. Appl. Biol. 114:243-254.

25. McNicol, R. J., Williamson, B., and Dolan, A. 1985. Infection of red raspberry styles and carpels by Botrytis cinerea and its possible role in post-harvest grey mould. Ann. Appl. Biol. 106:49-53.

26. Mueller, W. C., and Greenwood, A. D. 1978. The ultrastructure of phenolic-storing cells fixed with caffeine. J. Exp. Bot. 29:757-764.

27. Nair, N. G., and Allen, R. N. 1993. Infection of grape flowers and berries by Botrytis cinerea as a function of time and temperature. Mycol. Res. 97:1012-1014.
28. Nair, N. G., Guilbaud-Oulton, S., Barchia, I., and Emmett, R. 1995. Significance of carry over inoculum, flower infection and latency on the incidence of Botrytis cinerea in berries of grapevines at harvest in New South Wales. Aust. J. Exp. Agric. 35:1177-1180.

29. Pezet, R., and Pont, V. 1984. Botrytis cinerea: Activité antifongique dans les jeunes grappes de Vitis vinifera, variété Gamay. Phytopathol. Z. 111:73-81

30. Pezet, R., and Pont, V. 1986. Infection florale et latence de Botrytis cinerea dans les grappes de Vitis vinifera (var. Gamay). Rev. Suisse Vitic. Arboric. Hortic. 18:317-322.

31. Pezet, R., Viret, O., Perret, C., and Tabacchi, R. 2003. Latency of Botrytis cinerea Pers.: Fr. and biochemical studies during growth and ripening of two grape berry cultivars, respectively susceptible and resistant to grey mould. J. Phytopathol. 151:208-214.

32. Pratt, C. 1971. Reproductive anatomy in cultivated grapes-A review. Am. J. Enol. Vitic. 22:92-109.

33. Rawlins, T. E. 1933. Phytopathological and Botanical Research Methods. John Wiley \& Sons, New York.

34. Reynolds, E. 1963. The use of lead citrate at high $\mathrm{pH}$ as electron-opaque train in electron microscopy. J. Cell Biol. 17:208-212.

35. Spurr, A. R. 1969. A low-viscosity embedding medium for electron microscopy. J. Ultrastructural Res. 26:31-43.

36. Srinivasan, C., and Mullins, M. G. 1981. Physiology of flowering in the grapevine-A review. Am. J. Enol. Vitic. 32:47-63.

37. Swanepoel, J. J., and Archer, E. 1988. The ontogeny and development of Vitis vinifera L. cv. Chenin Blanc inflorescence in relation to phenological stages. Vitis 27:133-141.

38. Transmo, A., and Raa, J. 1977. The life cycle of the dry eye rot pathogen Botrytis cinerea Pers. on apple. Phytopathol. Z. 89:203-207.

39. Verhoeff, K. 1970. Spotting of tomato fruits caused by Botrytis cinerea. Neth. J. Plant Pathol. 76:219-226. 